\title{
CONSTITUCIÓN Y ECONOMÍA ${ }^{1}$
}

\author{
HELENA ALVIAR GARCÍA
}

This paper analyzes the relationship, in Colombia, between law and modernization until 1945, and, since then, between law and economic development. This last phase saw a transformation from an instrumental conception of law to an understanding of law as a state mechanism used to fulfil the goals of classical liberalism. It is from this perspective that the 1991 Constitution came to be seen as a source of institutions that block economic growth. This severely complicates the possibility of a dialogue between economists and lawyers, which cannot ignore the aims of development, nor can it ignore the conditions that a model of ideal liberal institutions imposes.

Esta presentación se enmarca dentro de un debate mucho más amplio y antiguo que se refiere a la relación entre el derecho y la modernización en un primer término y, a partir de 1945, a la relación entre derecho y desarrollo económico. Esta relación entendida en su sentido más amplio, en Colombia ha ido evolucionando desde la predominancia del derecho (teniendo la economía un papel secundario), pasando por una interpretación instrumental del derecho (entendiéndolo al servicio del desarrollo económico), a las aproximaciones teóricas más recientes que entienden el derecho como un obstáculo al desarrollo y que analizan la legislación, su creación, efectos y adjudicación judicial a través del uso de herramientas económicas. Este último enfoque implica una pérdida del espacio de discusión teórica jurídica y la colonización del debate por temas técnico-económicos. De esta manera, el marco de discusión se plantea en términos del análisis histórico y comparado del conjunto de instituciones que promueven y aseguran la asignación de recursos a través del mercado (el mecanismo idóneo y eficiente para la distribución) y cuyo efecto es un mejor desempeño económico. Como consecuencia, los conceptos relevantes son la

\footnotetext{
${ }^{1}$ Esta ponencia fue leída en el Foro sobre Constitución económica de Colombia, en marzo de 2002, en la Universidad Icesi.
} 
libertad económica, la libertad de empresa, la libre competencia y el desarrollo de instrumentos que fortalezcan la seguridad jurídica y protejan la propiedad privada. En la medida en que estos temas ganan terreno (con la inevitable consecuencia de excluir del debate a quienes no son expertos), otros van perdiendo relevancia. De esta manera, temas tales como la estructura del orden político, los límites e ideales de la justicia social, la intervención del Estado en la economía y los instrumentos para proteger los derechos económicos y sociales se vuelven conceptos marginales o, para ponerlo en términos de un neo-institucionalista colombiano, son 'frenos al alcance de las reformas liberales contenidas en la constitución'.'

Esta ponencia tiene como objetivo hacer un análisis histórico y comparado de los términos en los cuales ha evolucionado esta relación para demostrar que aún existen temas fundamentales que el derecho debe definir (por ejemplo, individualismo vs solidaridad, egoísmo vs altruismo, intervencionismo o no para la redistribución). Esta definición debe hacerse por cierto a partir de un diálogo con la economía; sin embargo, como abogados no debemos abandonar el espacio de discusión jurídica en aras de argumentos técnico-económicos: debemos tener la convicción que el derecho aún tiene mucho que aportar al debate y que solamente de un intercambio serio y profundo entre las dos disciplinas, entre los objetivos de desempeño económico y los objetivos de justicia social podremos promover intervenciones encaminadas a impulsar el bienestar de la mayoría de la población colombiana.

\section{Aspectos históricos de la relación entre derecho y desarrollo}

El concepto claro, concreto y definido de desarrollo económico se empezó a discutir, nacional e internacionalmente a partir de 1945³. Antes de 1945 existían diversas concepciones relacionadas con el tema del progreso en términos económicos. En su sentido más amplio, la búsqueda de la modernización, entendida como el conjunto de factores políticos, culturales y económicos que definen un país como moderno.

¿Qué se entiende, entonces, por lo 'moderno'? En primer lugar, puede entenderse como el propósito de distinguir el presente cristiano, del pasado pagano que caracterizó a los romanos. De esta manera, el vocablo expresa la conciencia de una época que se relaciona de una manera específica con el pasado y se ve a sí misma en movimiento, pasando de lo antiguo a lo nuevo. La idea de ser 'moderno' también se refiere a una ruptura con la idea de volver a los clásicos (considerados

\footnotetext{
2 Kalmanovitz, Salomón, «Constitución y Modelo Económico» en El Debate a la Constitución, Universidad Nacional de Colombia e ILSA, 2002, p.141.

3 Arndt, H.W., Economic Development, The History of an Idea, 1987, University of Chicago Press, pp. 9-49.
} 
durante algún tiempo y por algunos, fuente única de conocimiento) e implica una visión lineal de la historia que mira hacia el futuro, con una fe absoluta en el progreso del conocimiento hacia un perfeccionamiento social y moral.

Pero el proyecto modernizador fue formulado concretamente durante el siglo XVIII por los filósofos de la Ilustración y consiste en un esfuerzo por desarrollar los elementos característicos de una ciencia objetiva así como una serie de conceptos universales acerca de la moral y la ley. Cada una de esas áreas se consideraba como una unidad epistemológica coherente, delimitada por una lógica interna. Esta concepción de lo 'moderno' fue promovida o facilitada por tres revoluciones. Una revolución económica caracterizada por la consolidación del sistema capitalista y la producción industrial, una revolución política que introdujo las ideas del Estado liberal, democrático, moderno y una revolución cultural que secularizó la educación y la transmisión de valores culturales ${ }^{4}$.

De esta manera, la revolución económica es uno de los elementos de la modernización y como tal es el antecedente al concepto de desarrollo económico a nivel académico nacional e internacional. Esta modernización económica se refiere a la acumulación de capital para la industrialización. Miguel Urrutia la describe en los siguientes términos para el caso colombiano.

Aunque en historia económica es muy difícil identificar en cual-
quier país el momento en que se inicia el desarrollo económico mo-
derno, en el caso colombiano la década de los veinte se puede iden-
tificar como el momento en que se acelera perceptiblemente la for-
mación de capital y la tasa de crecimiento en el ingreso per capita.

${ }^{4}$ Ver Melo, Jorge Orlando, «Algunas Consideraciones Globales Sobre Modernidad y Modernización» en Colombia: El Despertar de la Modernidad, Fernando Viviescas y Fabio Giraldo (compiladores), Carvajal 1991, pp.231-232. Jorge Orlando Melo describe en mayor detalle estas revoluciones de la siguiente manera: En primer lugar la revolución económica, que generó por primera vez un sistema productivo en proceso continuo de crecimiento, capaz de sostener un aumento permanente y no cíclico de la población. Los elementos centrales de este proceso fueron el establecimiento del capitalismo, la vinculación estrecha entre el desarrollo tecnológico y el proceso económico, la creación de la industria fabril, la creciente utilización tecnológica de los conocimientos científicos y el surgimiento de una economía basada en el mercado de trabajo asalariado y en la propiedad privada de la tierra y los recursos productivos. En segundo lugar una revolución política que configuró los estados nacionales modernos, con un Estado con pretensiones de soberanía vinculado a una ciudadanía abstracta como fundamento de esa soberanía.En tercer lugar, se produjo una revolución cultural de grandes consecuencias. Entre el siglo XVI y el siglo XX se ha efectuado un paulatino desplazamiento de las formas de comunicación social. El papel de la Iglesia y de la familia en la transmisión de la tradición cedió ante la importancia creciente del sistema escolar formal, y en la medida en que se expandió la alfabetización, ante el surgimiento de la industria cultural. 
En esa época surge la industria moderna, y se comienza a crear un mercado nacional a través de la inversión en una infraestructura de transporte ${ }^{5}$.

Sin embargo, la costumbre de llamar a este conjunto de factores 'desarrollo económico' y el propósito de promoverlos para los países del Tercer Mundo, surgieron a partir de 1945. H.W. Arndt, en su libro Desarrollo económico: la historia de una idea, lo explica de la siguiente manera.

Las razones por las cuales el desarrollo económico de las naciones menos desarrolladas, que apenas había merecido atención al final de la Primera Guerra Mundial, fue universalmente considerada como una política nacional e internacional fundamental al final de la Segunda Guerra Mundial, no son difíciles de identificar. La guerra había cambiado el balance mundial de poder. Los antiguos poderes imperialistas surgieron debilitados de la guerra y los movimientos de independencia nacional fortalecidos. El incremento del poder de la Unión Soviética y el correspondiente aumento de la influencia comunista le dio a los países subdesarrollados el rango de países del Tercer Mundo, progresivamente capaces de tomar ventajas de la Guerra Fría entre los dos poderes y presionar por sus demandas. En Occidente, estas exigencias de poder se complementaron con el compromiso de la opinión pública a los principios liberales y humanitarios que encontraban el poder colonial y el desequilibrio entre los países pobres y ricos inaceptable .

Aunque el concepto no se había definido como proceso único y autónomo, existen antecedentes económicos, sociales, políticos y jurídicos que abrieron el camino a la creación del campo de conocimiento correspondiente al desarrollo económico. El momento a partir del cual se vinculó el proceso de modernización con la normatividad jurídica es incierto. Lo que es seguro es que esta interacción entre el derecho y el desarrollo comenzó mucho antes de 1945 y su proceso de estructuración nacional fue alimentado por diversos debates teóricos europeos. Jorge Orlando Melo describe así este proceso de estructuración en Colombia:

Los primeros esbozos de una ideología modernizadora se presentaron en la elite criolla neogranadina de la segunda mitad del siglo XVIII.

\footnotetext{
${ }^{5}$ Urrutia, Miguel, «La Creación de las Condiciones Iniciales para el Desarrollo: El Café» en 50 Años de Desarrollo Colombiano, La Carreta, 1979, p. 38.

${ }^{6}$ Arndt, H.W., ob.cit., p.50.
} 
Su percepción del atraso hispánico, y del atraso adicional en el que estaba nuestro territorio, estuvo vinculada desde el comienzo a la adopción de un pensamiento protoliberal, cercano al liberalismo europeo. El desarrollo de una economía capitalista, la igualdad legal de la población, la expansión de la educación, la ampliación de las oportunidades de dirección administrativa para los criollos...

Para 1850 este proyecto modernizador hacía parte del ideario fundamental de los grupos dirigentes del país, y sus defensores podían alegar que al menos en el plano político se encontraba muy avanzado, en la medida en que se había creado un estado independiente, cuyo sistema institucional se basaba en principios constitucionales y jurídicos similares a los de las más avanzadas naciones de Europa: legislación escrita, separación de poderes, funcionarios electivos mediante un sistema electoral limitado, derecho civil y derecho penal tomado de Francia?

Ahora, este proyecto modernizador sufrió adaptaciones y reveses al debatirse en el contexto colombiano. Dos pensadores fundamentales del siglo XIXMiguel Antonio Caro y Rafael Núñez (conservadores) - hicieron esfuerzos para adaptar la teoría liberal clásica, desde su perspectiva, a las condiciones colombianas. En este orden de ideas, es importante establecer cúales eran las diferencias entre liberales y conservadores en el siglo XIX.

Ambos (miembros de los partidos liberal y conservador) eran librecambistas y con mayor o menor fuerza aprobaban la idea de la división internacional del trabajo que atribuía a los países latinoamericanos el papel de productores de materias primas agrícolas y mineras y el de consumidores de manufacturas baratas producidas por las metrópolis industriales...Sin embargo desde los orígenes de la República hubo en el seno de la clase dirigente discrepancias en materias religiosas y educativas suficientes para alimentar violentos conflictos. Hacia 1850 los liberales colombianos siguiendo las huellas de los europeos eran partidarios de la separación de la Iglesia y el estado, de la libertad de cultos, de la educación laica y de la no intromisión de la Iglesia en la política y de la reducción del poder económico que le daba su carácter de propietaria de tierras y beneficiaria de capitales dados a censo. Los conservadores por su parte defendían la unión

\footnotetext{
${ }^{7}$ Jorge Orlando Melo, Algunas consideraciones globales sobre modernidad y modernización en Fernando Viviescas y Fabio Giraldo (compiladores), Colombia: El Despertar de la Modernidad, Carvajal (1991), pp. 231 y 232.
} 
íntima de las dos potestades, hasta llegar a una posición rectora de la Iglesia frente al poder civil y considerar la religión católica como elemento básico del orden social...

Estas ideas conservadoras en cuanto a temas económicos se centraban en una crítica a la economía libre y una convicción de que el Estado debía dar soluciones a los problemas sociales y económicos del pueblo. Tanto Caro como Núñez, fueron defensores de un Estado fuerte, centralizado y eficaz en sus funciones jurídicas y económicas, con fuertes limitaciones a los derechos individuales en beneficio de la sociedad. ${ }^{9}$ Sus ideas fueron luego traducidas en la Constitución de 1886 que consagró un Estado centralizado, autoritario y caracterizado por una aceptación del papel dominante de la iglesia, el autoritarismo presidencial y la limitación de los derechos individuales ${ }^{10}$. Al mismo tiempo, los constituyentes de ese momento no consideraron que los temas económicos debían tener capítulos o artículos exclusivos y optaron porque los temas económicos se manejaran por medio de leyes. Los temas económicos se encontraban dispersos por todo el ordenamiento, no se consagró el principio liberal de la libertad económica; la existencia de la libertad de empresa se infería interpretando el contenido y alcance del artículo 39 sobre libertad de trabajo ${ }^{11}$ y el derecho de propiedad se encontraba consagrado en el artículo 32.

La primera reforma que abre el paso para un diálogo entre los objetivos de modernización económica y el derecho es la reforma constitucional de 1936. En esa época existía la convicción entre los miembros progresistas del partido liberal de que se necesitaba transformar el contenido político de las directrices del partido por dos razones fundamentales, en primer término para poner fin al escalamiento en los conflictos sociales y en segundo lugar para obtener los votos de los trabajadores urbanos y rurales. Una vez el ala progresista del partido liberal estuvo en el poder, necesitaba moldear este cambio ideológico en términos constitucionales y legales. Como consecuencia, en 1934, el Ministro del Interior Darío Echandía, presentó una reforma constitucional cuya justificación se encontraba en su deseo de apartarse del individualismo consagrado en la Constitución de 1886 y reemplazarlo por un concepto de solidaridad, más acorde con la realidad social, económica y política de

\footnotetext{
8 Jaramillo Uribe, Jaime, «Etapas y Sentido de la Historia Colombiana» en Colombia Hoy, Siglo XXI editores, 1990, p. 39.

${ }^{9}$ Jaramillo Uribe, Jaime, El Pensamiento Colombiano en el Siglo XIX. Temis, 1982, p. 261-273.

${ }^{10}$ Melo, Jorge Orlando, «La República Conservadora (1880-1930)» en Colombia Hoy, Siglo XXI editores, p.61.

${ }^{11}$ Perry Rubio, Guillermo, «Estado y Sector Privado en la Constitución de 1991» en

Constitución Económica Colombiana, El Navegante Editores, 1996, pp. 123-143.
} 
un país que estaba sufriendo los efectos extremos del sistema capitalista ${ }^{12}$. Darío Echandía mismo resumiría los objetivos de la reforma:

Como véis, honorables Representantes, el proyecto sustituye la concepción excesivamente individualista de los derechos privados que caracteriza la Constitución actual, por otra que considera que el derecho individual debe ejercitarse como una función social y debe tener como límite la conveniencia pública. El derecho privado como función social por oposición al derecho privado absoluto: tal es la última razón del proyecto que el Gobierno somete a vuestra consideración. ${ }^{13}$

Esta incorporación de la función social de los derechos tiene importantes consecuencias en el derecho constitucional colombiano debido a que transforma las actividades y objetivos del Estado y al mismo tiempo establece nuevas limitaciones al derecho de propiedad. En cuanto a la función del Estado, ésta no sólo se debe limitar a proteger a los individuos y sus derechos individuales, sino que debe regular la economía para crear los servicios públicos que permitan el ejercicio plenas de las actividades sociales. En cuanto a la propiedad establece claramente que tiene una función social. De esta manera, los artículos reformados decían lo siguiente:

Art. 10 - Se garantiza la propiedad privada y los demás derechos adquiridos con justo título, con arreglo a las leyes civiles, por personas naturales o jurídicas, los cuales no pueden ser desconocidos ni vulnerados por leyes posteriores. Cuando de la aplicación de una ley expedida por motivos de utilidad pública o interés social, resultaren en conflicto los derechos de particulares con la necesidad reconocida por la misma ley, el interés privado deberá ceder al interés público o social. La propiedad es una función social que implica obligaciones.

Art. 11-El Estado puede intervenir por medio de leyes en la explotación de industrias o empresas públicas o privadas, con el fin de racionalizar la producción, distribución y consumo de las riquezas, o de dar al trabajador la justa protección a la que tiene derecho.

Parágrafo. Las leyes que se dicten en ejercicio de la facultad que otorga este artículo requieren para su aprobación el voto favorable de la mayoría absoluta de los miembros de una y otra Cámara. ${ }^{14}$

\footnotetext{
${ }^{12}$ Alviar García, Helena, «Leon Duguit and the 1936 Colombian Constitutional Reform», Trabajo presentado en Harvard Law School, 8 de diciembre del 2001.

${ }^{13}$ Dario Echandía citado por Tirado Mejía, Alvaro y Velásquez, Magdalena, La Reforma Constitucional de 1936, p. 162.
} 
En este momento es importante hacer una pausa para reflexionar acerca de las características fundamentales de esta reforma para los objetivos generales de esta exposición. Aunque no se habla de desarrollo económico como lo hará en su momento la reforma del 68, es interesante ver que se tenía plena confianza en que, al cambiar el fundamento ideológico de la Constitución, se estaría ejerciendo una influencia clara y directa sobre la función del Estado y el régimen de propiedad. En este sentido, al hacerse esta transformación del Estado, los argumentos económicos encajarían dentro de esta nueva concepción y por lo tanto eran secundarios en la reforma.

A partir de 1945 a nivel internacional, y a nivel nacional concretamente con la reforma de 1968, esta relación entre derecho y desarrollo empezó a transformarse. De esta manera, en la reforma de 1968, se empieza a delimitar el debate jurídico a través de los objetivos de desarrollo económico y a mirar el derecho como instrumento para promover el desarrollo. Se podría decir que esta vinculación con objetivos de desarrollo económico, comienza a des-humanizar el debate jurídico, que empezará a ser planteado más y más en términos técnico-económicos y menos en relación con el individuo o la sociedad. La siguiente cita, tomada de un informe de la Presidencia de la República a través del cual se justificaba la reforma, ilustra esto.

En este orden de ideas, el tránsito del Estado gendarme al Estado para el desarrollo, impone también la sustitución de la mentalidad arcaica para la política por un espíritu y una inteligencia dinámicos y audaces. No se le oculta al autor de este informe que cuando en Colombia se alude a una mayor dotación de facultades o poderes constitucionales al órgano ejecutivo una inmediata reacción de desconfianza y temor pone en estado de alerta a la clase política y a la opinión pública ${ }^{15}$.

Para el tema que nos interesa, la reforma le dio al Ejecutivo la iniciativa legislativa en materias como normas orgánicas del presupuesto, planes y programas de desarrollo, planes de obras públicas, inversiones públicas y participaciones en las rentas nacionales. Estableciendo de esta manera que el ejecutivo podía canalizar mejor la relación entre los objetivos técnico-económicos y la intervención por medio de la regulación:

La vida actual es tan compleja que, de un lado, muchos problemas de la vida social deben recibir una reglamentación administrativa y no legislativa, y, por otra parte, es el Ejecutivo quien juega predo-

\footnotetext{
${ }^{14}$ Tirado Mejía, Alvaro y otra, ob.cit., pp. 137 y 139.

${ }^{15}$ Presidencia de la República, Historia de la Reforma Constitucional de 1968, Bogotá, Imprenta Nacional 1969, p. 77.
} 
minantemente el papel en el procedimiento legislativo. Para preparar una ley es preciso tener muchos especialistas y contar con la competencia técnica de un gran número de sabios, de técnicos, de administradores, de funcionarios etc. ${ }^{16}$

La primera materia que, que por lo tanto, será necesario estudiar es la concerniente a la distribución de competencias entre el Congreso y el ejecutivo. El punto presenta especial importancia porque desde las reformas constitucionales de 1936 y 1945 que contemplaron la intervención estatal en la economía e introdujeron en la carta el concepto del plan, ha avanzado considerablemente la técnica de la planeación y de los medios para ejecutar los planes de desarrollo. Quizá en ningún otro campo se presenta una desproporción más grande entre el progreso de las técnicas económicas y la imperfección de los instrumentos político jurídicos ${ }^{17}$.

Internacionalmente, en esta misma época se formó el movimiento de académicos norteamericanos interesados por el law and development, derecho y desarrollo. Para este grupo de académicos, la configuración de un determinado sistema legal (el sistema legal liberal) promovería la industrialización y consolidación del sistema capitalista por un lado y fortalecería la modernización política por otro. Este concepto era la aplicación de la interpretación de Max Weber respecto de las condiciones que permitieron la industrialización en Europa, a los países subdesarrollados. Weber desarrolló esta idea en Economía y Sociedad. El académico de la escuela de derecho y desarrollo, David Trubek, resume esta relación:

El evento que trató de explicar Weber fue la razón por la cual el sistema moderno de capitalismo industrial surgió en Europa y no en otras partes del mundo. Weber consideraba que el derecho había jugado un papel esencial en el recuento. La ley europea contenía unas características únicas, diferentes de los sistemas jurídicos de otras civilizaciones, que facilitaron el surgimiento del capitalismo ${ }^{18}$.

Durante la década de los noventa, debido en gran parte al resurgimiento de la función del Estado gendarme concebido por el liberalismo clásico -el neoliberalismola relación entre derecho y el desarrollo se transformó, y empezó a entenderse el

\footnotetext{
${ }^{16}$ Presidencia de la República, ob.cit., pag. 13.

${ }^{17}$ Presidencia de la República, ob.cit., pag. 13.

${ }^{18}$ Trubek, David, "Max Weber on Law and The Rise of Capitalism», Wisconsin Law Review, 1972, p. 721.
} 
derecho como un impedimento. Esta idea tomó fuerza a partir de un documento publicado en 1983 por el Banco Mundial en el que se establecía cómo algunas políticas gubernamentales (controles sobre el comercio exterior, control cambiario y subsidios) creaban distorsiones en el mercado que impedían el correcto funcionamiento del mismo y como consecuencia impedían el crecimiento económico ${ }^{19}$.

\section{Diversas interpretaciones sobre los aspectos económicos de la Cons- titución de 1991}

En líneas generales, la Constitución de 1991 mantuvo el equilibrio (presente desde 1936 en el constitucionalismo colombiano) entre los derechos de propiedad privada y libertad económica con la función social de la propiedad y la intervención del Estado en la economía. Para los miembros del partido liberal, este equilibrio es deseable para un país como Colombia. Esta opinión es clara en la siguiente cita de la Declaración expedida por los constituyentes liberales:

Buscaremos fortalecer y hacer eficaz la libre competencia económica, a tiempo que procuraremos un Estado capaz de dirigir la economía en beneficio de toda la sociedad. Nos proponemos sentar las bases para la construcción de un Estado y una sociedad modernos y justos, 'con tanto mercado como sea posible y con tanta intervención como sea necesaria. ${ }^{20}$

Recientemente, sin embargo, como lo dije al comienzo, se ha generalizado una interpretación neo-institucionalista de la Constitución, que se enmarca dentro del análisis económico del derecho; es decir, dentro del uso de herramientas económicas para analizar la formación, estructura, procesos jurídicos, el impacto económico de la ley y las instituciones legales ${ }^{21}$. De acuerdo con esta interpretación, la fórmula para lograr el desarrollo económico sería una en la que el Estado se encargue exclusivamente de promover la libertad económica para estimular el intercambio mercantil, proteja los derechos de propiedad privada, establezca reglas para la regulación de los mercados y provea de seguridad y justicia. Claramente, la idea liberal clásica de las funciones del Estado. En este orden de ideas, las instituciones que se van a desarrollar a

\footnotetext{
${ }^{19}$ Alviar García, Helena, The Place of Economic Development and Feminist Theory in Legal

Transformation, Tesis Doctoral, Harvard Law School, 2001, pp. 23-25.

${ }^{20}$ Perry Rubio, Guillermo, ob.cit., p. 126.

${ }^{21}$ Kalmanovitz, Salomón, ob.cit.
} 
partir de la Constitución de 1991 impiden el desarrollo económico, debido a que existe una incompatibilidad teórica entre el intervencionismo que lleva a la protección de derechos económicos y sociales con el establecimiento y la protección de un orden de mercado. En esta medida, la constitución está mal diseñada pues no establece unívocamente principios liberales y, en cambio, «no se desprendió con firmeza de una concepción paternalista y caritativa del Estado que fue la base moral de la constitución de $1886^{22}$ ».

Según Kalmanovitz, esta concepción tradicional habría impedido el desarrollo económico en Colombia. Así lo expresa en la evaluación que hace de los 10 años de la Constitución:

La matriz institucional legada por la tradición hispánica le da forma a un Estado que trata a los individuos como niños, que intenta resguardarlos en sus actos y contratos, porque no saben lo que hacen, porque dejados a su arbitrio se harían daño, porque no son libres, porque deben ser guiados continuamente por la sapiencia del Estado iluminado por el amor de Cristo. Esto ha cambiado en buena medida con la modernización del país y su acelerada secularización, pero estas actitudes todavía sobreviven en muchos actos de gobierno y en algunos fallos de los altos magistrados, mientras que muchos ciudadanos se sienten como súbditos carentes de iniciativa y exigen al padre-Estado que satisfaga todas sus necesidades. Las políticas y los fallos paternalistas enfatizan los derechos y descuidan los deberes de los ciudadanos menores de edad. Una concepción democrática debe enfatizar que el poder del Estado depende de la tributación de sus ciudadanos-mayores de edad. Todos deben comprometerse con la comunidad para tributar y construir el Estado. ${ }^{23}$

Las consecuencias de esta contradicción entre Estado interventorpaternalista y Estado gendarme, en términos de Kalmanovitz, se configuran en la labor de la Corte Constitucional:

Los problemas de la implementación de las directrices contenidas en la constitución fueron los de escoger cuál sería predominante sobre las demás, tarea que se le encomienda a la Corte Constitucional. Algunos magistrados de la primera Corte Constitucional cuy período culminó en marzo de 2001, debilitaron los

${ }^{22}$ Ibid., p. 119

${ }^{23}$ Ibid., p. 121. 
elementos liberales contenidos en la ley de la nación y reforzaron los temas introducidos por los sectores socialdemócratas y conservadores...La primera Corte ha interpretado la Constitución de 1991 como dando lugar a un grado de intervención estatal muy alto, que la mayoría de los constituyentes de 1991 no aprobaría. ${ }^{24}$

\section{Conclusiones}

En el diálogo entre el derecho y la modernización económica o el derecho y el desarrollo, tanto abogados como economistas hemos pecado por no entender los argumentos y estructura del análisis hecho por cada una de las disciplinas. En un primer momento, los abogados daban poca importancia a los factores económicos y entendían que estos vendrían como consecuencia de un determinado orden político y social. En un segundo período, en el cual la economía empezó a ganar terreno como campo de conocimiento científico al cual solo accede un grupo de expertos, el derecho empezó a entenderse al servicio del bien mayor, es decir las fórmulas de desarrollo económico. Sin embargo, durante este período, que podríamos relacionar con el Estado intervencionista -no sólo en Colombia sino en América Latina- todavía existía la convicción de que hay temas que deben ser discutidos en términos de ideología política y social y que hay algunas funciones de redistribución que solamente el Estado puede cumplir. A partir de los noventa, la intervención del Estado (Estado entendido en su sentido más amplio, incluyendo los jueces, de acuerdo con el análisis de Kalmanovitz) se ha visto como un obstáculo para el desarrollo. En esta medida, el examen al que se someten las instituciones, es si promueven o no el libre desarrollo del mercado. Como consecuencia, el debate ideológico, teórico, jurídico se mete en una camisa de fuerza que permite solamente la comparación de una situación con un modelo de instituciones liberales ideales.

De esta manera, los economistas consideran que los abogados son ingenuos en temas económicos y los abogados acusan a los economistas de ser insensibles ante los temas sociales y políticos. La manera de resolver este conflicto no es la forma tradicional de los debates, es decir, dándole importancia polémica a cada uno de los polos de la discusión (primero el jurídico y luego el económico). Se hace imprescindible un diálogo entre iguales por parte de quienes ejercen cada una de las dos disciplinas, partiendo de un entendimiento complejo y no superficial de los alcances y de los límites que tiene cada uno de los discursos, con el fin de llegar a acuerdos reales en términos de progreso económico, social y político.

\footnotetext{
${ }^{21}$ Kalmanovitz, Salomón, ob.cit.
} 